\title{
XLVIII. The origin of radiation in a gaseous explosion
}

\section{Major W.T. David M.A. M.Sc.}

To cite this article: Major W.T. David M.A. M.Sc. (1919) XLVIII. The origin of radiation in a gaseous explosion, Philosophical Magazine Series 6, 38:226, 492-494, DOI: $10.1080 / 14786441008635976$

To link to this article: http://dx.doi.org/10.1080/14786441008635976

曲 Published online: 08 Apr 2009.

Submit your article to this journal

Џ Article views: 3

Q View related articles $\asymp$ 
If $\tanh \alpha$ or $\sqrt{1-a^{2} / c^{2}}$ is a rational number, say $=p / q$, where $p$ and $q$ are integers with no common factor, the curve is algebraic. It has $2 p$ cusps and is re-entrant after $q-p$ revolutions about the pole.

(3) In the intermediate case $c=a$, the integral is

$$
\theta=\cot \frac{1}{2} \phi \text {, }
$$

where $\theta=0, \phi=180^{\circ}$ initially. If $\theta=0, \phi=0$ initially, $W$ is at the pole $A$ and remains there. There is therefore only the outer branch remaining. It is a spiral tending to the pole, and having a cusp at a distance $2 a$.

In each case the C-locus, or evolute of the slip-curve, has asymptotes touching the circle $r=c$ and cutting the slipcurve orthogonally at the points of inflexion.

Victoria Univ. Coll.,

Wellington, N.Z.

Sept. 25th, 1918.

XLVIII. The Origin of Radiation in a Gaseous Explosion. By Major W. T. David, M.A., M.Se.*

1. $\mathrm{T}$ is now well known that inflammable gaseous mixtures 1 emit radiation strongly both during explosion and subsequent cooling. In some experiments made in 1909 and 1910 the radiation emitted by exploded coal-gas and air mixtures was found to amount to as much as 25 per cent. of the total heat of combustion of the coal-gas present in the explosion-vessel $\dagger$.

2. 'The British Association Committee on Gaseous Explosions were much interested in these results, and for a time their discussions mainly centred round the question as to the probable origin of the radiation. The chemists on the Committee were of the opinion that the radiation was wholly due to chemical causes. They believed that gases which are capable of emitting radiation can only do so when undergoing chemical or quasi-chemical reaction. This opinion was not generally held. Many of the members held the view that the chemical activities which may be proceeding during the cooling of the exploded mixture were not sufficient

* Communicated by the Author.

$\dagger$ Hopkinson, Roy. Soc. Proc. A. vol. lxxxiv. p. 155. David, Phil. Trans. A. vol. cexi. p. 375 . 
to account for the large emission during this epoch. They telt that much of this radiation must be due to thermal causes. All were agreed, however, that part of the emission recorded was due to chemical causes.

3. In a previous paper * the writer examined this question in some detail, and he came to the conclusion that it was difficult to account for the large emission during cooling unless the gaseous mixture was capable of emitting radiation in virtue of its temperature. He pointed out, however, that there was no experimental work which could be regarded as proving conclusively that a gas may emit radiation in virtue of its temperature alone. But on reviewing the matter recently he has come to the conclusion that the experiments he made with bydrogen and air mixtures $\dagger$ do afford fairly conclusive evidence that water vapour has a pure temperature emission. Chemists appear to be firmly of opinion that the chemical reactions involved in the formation of $\mathrm{H}_{2} \mathrm{O}$ molecules are simple, and are completed at the moment of attainment of maximum pressure, or very shortly afterwards, so that the cooling of a hydrogen and air mixture after explosion would appear to take place undisturbed by chemical or quasichemical reactions. The large emission of radiation during the cooling of an exploded hydrogen and air mixture would therefore appear to be thermal in origin.

4. The molecules of $\mathrm{CO}_{2}$ are capable of vibrations of the same order of frequency as those peculiar to $\mathrm{H}_{2} \mathrm{O}$ molecules; and it is considered that what is true of the latter in this respect is probably true of the former. There is certainly nothing in the writer's experiments on radiation from exploded gases to indicate that the $\mathrm{CO}_{2}$ molecules behave differently From $\mathrm{H}_{2} \mathrm{O}$ molecules, except that the former radiate more powerfully. (This, however, would be expected from a study of the infra-red absorption spectra of both gases.) At any given temperature the rate of emission of radiation from an exploded liydrogen and air mixture containing about 30 per cent. of steam (the remainder almost entirely nitrogen) is only a little less than that from an exploded coul-gas and air mixture which contains about 8.5 per cent. of $\mathrm{CO}_{2}, 20$ per cent. steam, and the remainder almost entirely nitrogenf.

5 . The radiation measured in the gaseous explosion experiments was mainly of large wave-length $(2 \mu$ and over).

* Phil. Mag. Feb. 1913, p. 256.

+ Phil. Trans. A. vol. cexi. p. 391 .

$\ddagger$ Phil. Trans. A. vol. ccxi. p. 386 (fig. 9). 
The energy in the radiation of shorter wave-length (which includes the luminous radiation) is small, and an analysis of the radiation emitted indicated that the emission of such radiation takes place only during explosion and in the very early stages of cooling*. It is probable, therefore, that the emission of the short wave-length radiation is dependent upon chemical activity.

6. This, together with the fact that the very large emission of radiation during the explosion period (i.e. the period between ignition of the gaseous mixture and the attainment of maximum pressure) is partly independent of temperature + , leads the writer to believe that the energy of chemical combination passes partly into the form of both high and low frequency vibrations of the internal parts of the combining molecules. Various considerations based partly on his experimental work and partly upon Jeans's theory+l lead to the vien that the energy in the high-trequency vibrations is damped wholly by the emission of radiation, while that in the lowfrequency vibrations (corresponding to radiation of wavelength $2 \mu$ and over) is damped partly by emitting radiation and partly (and mainly) by a transference during molecular collisions from it to the other forms of molecular energy (translational and rotational). In the cass of the hightrequency vibrations the damping proceeds until the energy in them is reduced to zero; but in the case of the lowfrequency vibrations the energy will only be reduced to all equilibrium value (which depends mainly on the gas temperature) $\$$. After this value has been reached the energy which they lose by radiation will tend to be restored to them during collisions.

* David, Phil. Trans. A. vol. ccxi. p. 390.

+ Darid, Phil. Trans. A. vol. cexi. p. 381 .

$\ddagger$ See his 'Dynamical Theory of Gases,' Camb. Univ. Press, 1904, chap. ix.

$\S$ In this connexion see theory suggested in Phil. Mag. Feb. 1913, p. 267. 